\section{A FORTRAN 77 program for averaging correlation coefficients}

\section{N. CLAYTON SILVER \\ and SARAH C. HOLLINGSWORTH \\ Appalachian State University, Boone, North Carolina}

Because the correlation coefficient is extremely variable, it is often recommended that large samples be used to obtain stable estimates of the population correlation. When small sample sizes are repeatedly tested (Carter, Kennedy, \& Bittner, 1981; Mackaman, Bittner, Harbeson, Kennedy, \& Stone, 1982), however, it has been shown that estimates of the population correlation become more stable when correlations are averaged over these measures (see Dunlap, Jones, \& Bittner, 1983; Dunlap, Silver, \& Bittner, 1986; Dunlap, Silver, Hunter, \& Bittner, 1985).

A number of different methods for averaging correlations have been studied. Silver and Dunlap (1987) found that the backtransformed average $z$ produced more accurate estimates of the population correlation than did the arithmetic average $r$ when the sample sizes were small and the population correlation exceeded .5. Furthermore, Dunlap, Silver, and Phelps (1988) found that the backtransformed average $z$ was less biased and had greater precision than did a procedure proposed by Kaiser (1968), which used the first eigenvalue in an intercorrelation matrix, particularly when sample sizes were small.

The backtransformed average $z$ procedure for averaging correlations involves transforming each correlation to Fisher's $z$ (1921), which distributes approximately normal, where

$$
z=0.5 \log _{e}[(1+r) /(1-r)] .
$$

The Fisher zs are averaged by the following equation (cf. Fisher, 1973; Lindeman, Merenda, \& Gold, 1980):

$$
z_{\mathrm{av}}=\frac{\left(n_{1}-3\right) z_{1}+\left(n_{2}-3\right) z_{2} \ldots+\left(n_{k}-3\right) z_{k}}{n_{1}+n_{2}+\ldots+n_{k}-3 k},
$$

where $n$ is the sample size for a particular correlation and $k$ is the number of correlations. When the sample sizes for each correlation in the matrix are equal, this equation reduces to

$$
z_{\mathrm{av}}=\left(z_{1}+z_{2}+\ldots z_{k}\right) / k
$$

where $k$ is the number of correlations. After the Fisher $z$ s have been averaged, the average $z$ is backtransformed to $r$ via the following equation:

$$
r=\left(e^{2 z}-1\right) /\left(e^{2 z}+1\right) \text {. }
$$

Correspondence may be addressed to N. Clayton Silver, Department of Psychology, Appalachian State University, Boone, NC 28608.
Furthermore, there are instances when one can test the null hypothesis that $\bar{r}=0$ (cf. Fisher, 1973; Lindeman et al., 1980). To test this hypothesis, the following equation is used (cf. Fisher, 1973; Lindeman et al., 1980):

$$
z=z_{\mathrm{av}} \sqrt{n_{1}+n_{2}+\ldots n_{k}-3 k}
$$

The program. The user is prompted interactively for the number of correlations. This should be the number of correlations on the upper or lower half of the matrix excluding the diagonal. Next, the user is asked if the sample size is equal for each correlation in the matrix. If the sample size is equal for each correlation, the program converts each correlation to Fisher's $z$, sums up the Fisher $z s$, and divides by the number of correlations the user had input. Next, the average $z$ is backtransformed to average $r$. If the sample size is not equal, then a weighted average of Fisher $z s$ is computed (see Equation 2). This weighted average is backtransformed to average $r$. The program then computes the test of the null hypothesis that $\bar{r}=0$. The output consists of the backtransformed average $z$, the $z$ value from the significance test, and the probability of rejecting the null hypothesis of $\bar{r}=0$ using the function ZPRB (Dunlap \& Duffy, 1975).

Requirements. The program is written in single precision FORTRAN 77 and runs on a VAX 8550 computer. Because the program is interactive, the input and output are via the terminal. There are no nonstandard FORTRAN statements, however, users might have to substitute a format statement number for the free format symbol "*" in the READ statement on some systems. Also, Unit 5 has been assigned by default to the keyboard and CRT screen on our system.

Availability. A listing of the program may be obtained at no charge from N. Clayton Silver.

\section{REFERENCES}

Carter, R. C., Kennedy, R. S., \& Bittner, A. C. (1981). Grammatical reasoning: A stable performance yardstick. Human Factors, 23, 587-591.

DUNLAP, W. P., DUfFY, J. A. (1975). FORTRAN IV functions for calculating exact probabilities associated with $z, x^{2}, t$, and $F$ values. Behavior Research Methods \& Instrumentation, 7, 59-60.

DunlaP, W. P., Jones, M. B., Birtner, A. C. (1983). Average correlations vs. correlated averages. Bulletin of the Psychonomic Society, 21, 213-216.

DunlaP, W. P., Silver, N. C., \& BittNer, A. C. (1986). Estimating reliability with small samples: Increased precision with averaged correlations. Human Factors, 28, 685-690.

Dunlap, W. P., Silver, N. C., Hunter, R. E., Bittner, A. C. (1985). Averaged cross-correlations: A methodology for validity assessment in small samples. In R. Eberts \& C. G. Eberts (Eds.), Trends in ergonomics/human factors (Vol. 2, pp. 13-21). Amsterdam: Elsevier.

Dunlap, W. P., Silver, N. C., Phelps, G. R. (1988). A Monte Carlo study of using the first eigenvalue for averaging intercorrelations. Educational \& Psychological Measurement, 47, 917-923.

FISHER, R. A. (1921). On the probable error of a correlation deduced from a small sample. Metron, 1, 1-32. 
FISHER, R. A. (1973). Statistical methods for research workers. New York: Hafner.

Kaiser, H. F. (1968). A measure of the average intercorrelation. Educational \& Psychological Measurement, 28, 245-247.

Lindeman, R. H., Merenda, P. F., \& Gold, R. Z. (1980). Introduction to bivariate and multivariate analysis. Dallas: Scott, Foresman.
Mackaman, S. L., Bittner, A. C., Harbeson, M. M., Kennedy, R. S., \& Stone, D. A. (1982). Performance evaluation tests for environmental research (PETER): Wonderlic Personnel Test. Psychological Reports, 51, 635-644.

Silver, N. C., \& DUNLAP, W. P. (1987). Averaging correlation coefficients: Should Fisher's $z$ transformation be used? Journal of Applied Psychology, 72, 146-148.

\section{APPENDIX}

FORTRAN 77 Program for Averaging Correlations and Testing the Average Correlation for Significance

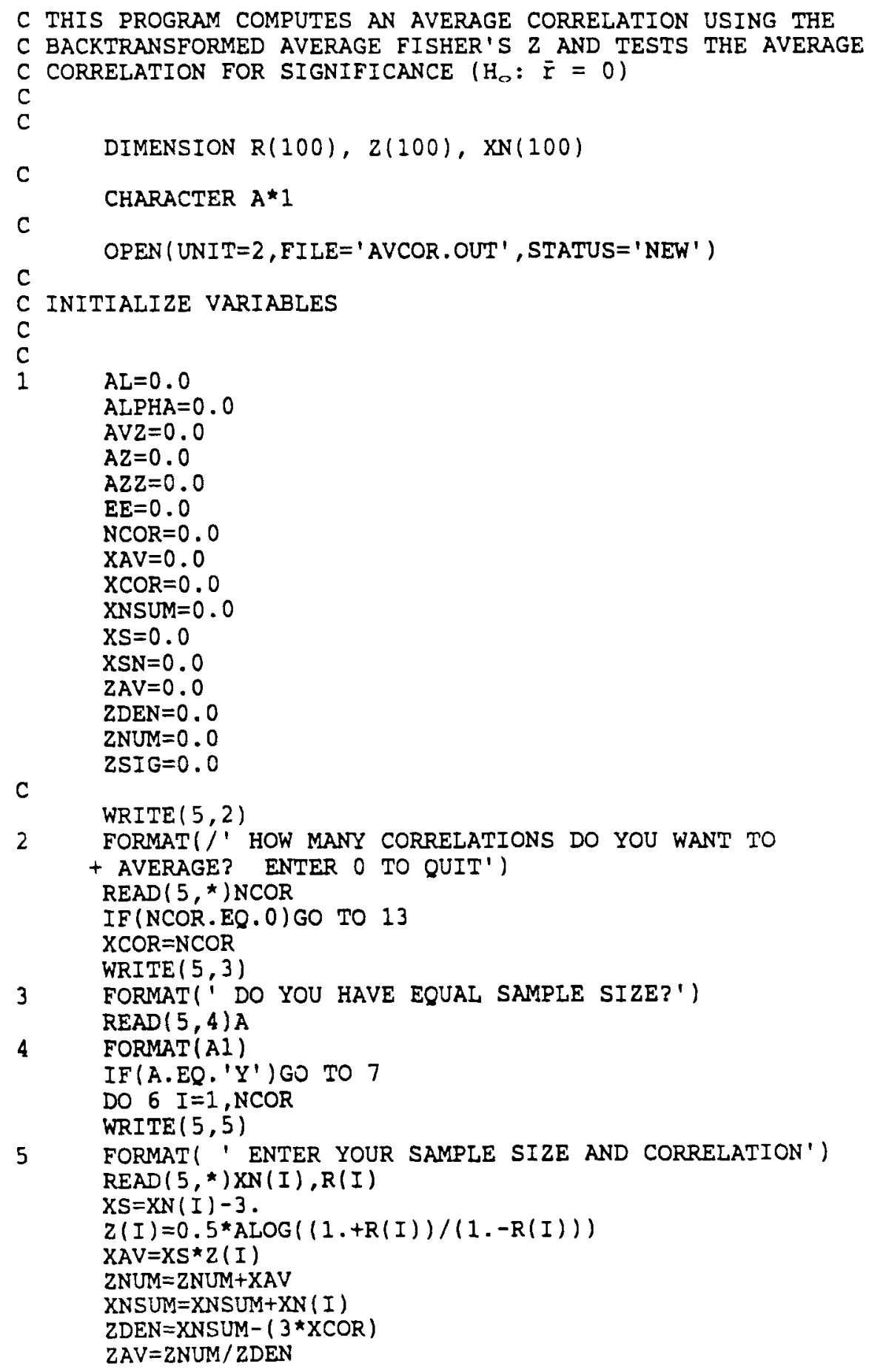


APPENDIX (Continued)

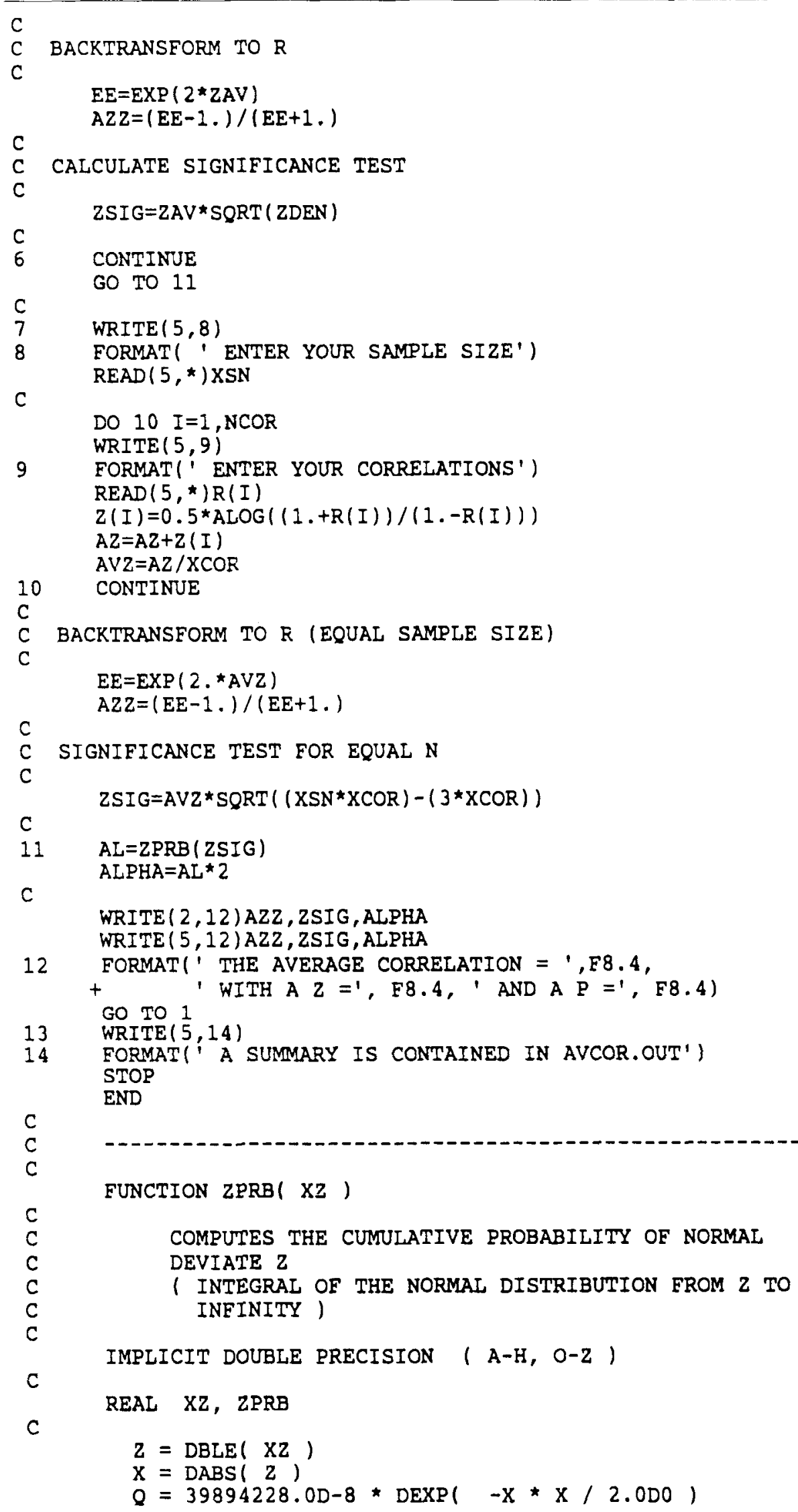




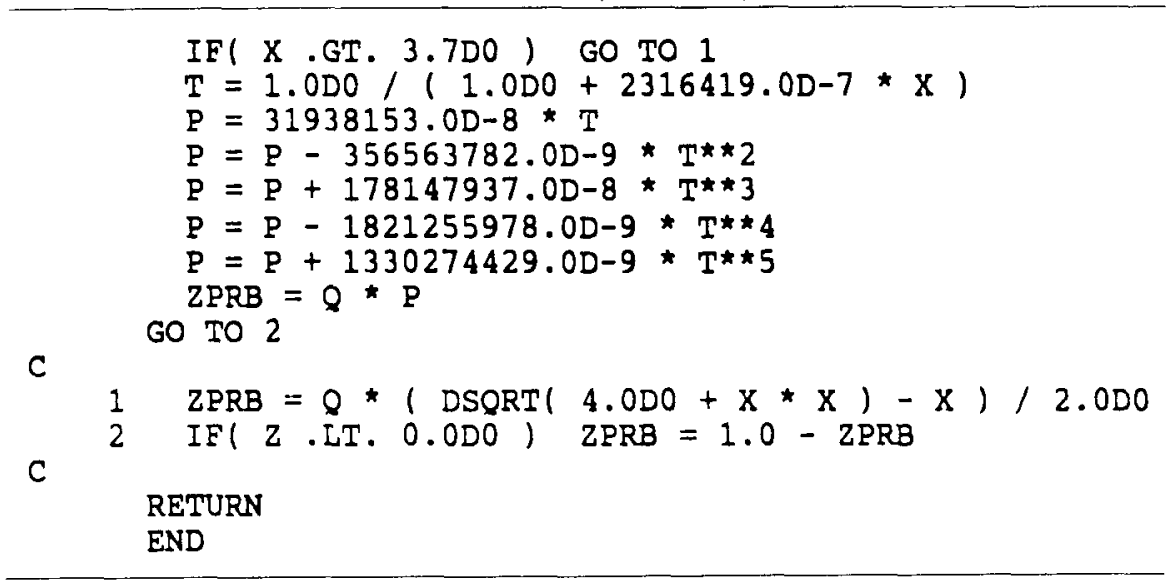

(Manuscript received August 23, 1989;

revision accepted for publication October $11,1989$. ) 